Check for updates

Cite this: RSC Adv., 2017, 7, 38210

Received 4th June 2017

Accepted 21st July 2017

DOI: 10.1039/c7ra06238a

rsc.li/rsc-advances

\section{An efficient iodide ion chemosensor and a rewritable dual-channel security display material based on an ion responsive supramolecular gel $\uparrow$}

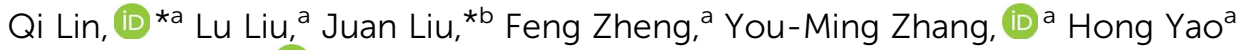 \\ and Tai-Bao Wei iD *a
}

By introducing multi-self-assembly driving forces, coordination binding sites and signal groups into the same molecule, a well designed functional gelator G1 was synthesized. The gelator G1 could form a stable $\mathrm{Pb}^{2+}$-coordinated supramolecular metallogel $(\mathrm{PbG})$ accompanied with aggregation-induced fluorescence emission (AIE). PbG shows the reversible selective fluorescent response for $\mathrm{I}^{-}$under a gelgel state. The detection limit of $\mathrm{PbG}$ for $\mathrm{I}^{-}$is $1.0 \times 10^{-7} \mathrm{M}$. The AlE fluorescence of $\mathrm{PbG}$ could be reversibly switched "on-off-on" under gel-gel states via alternatively adding $\mathrm{I}^{-}$and $\mathrm{Pb}^{2+}$ water solution into PbG. Other anions could not induce similar stimuli-response for PbG. Interestingly, when a writing brush dipped in $\mathrm{I}^{-}$water solution was used to write on the xerogel film of $\mathrm{PbG}$, the film did not show any color changes. However under UV at $365 \mathrm{~nm}$, a clear dark writing image appeared. This dark writing could be erased by brushing $\mathrm{Pb}^{2+}$ on the film. More interestingly, when the $\mathrm{PbG}$ film containing the invisible $\mathrm{I}^{-}$writing was exposed to iodine vapor, a clear brown writing appeared on the film. However, when this film was placed under the room atmosphere for one minute, the brown writing gradually disappeared. Therefore, the PbG film could act as not only a convenient reversible $\mathrm{I}^{-}$detection test kit, but also an erasable dual-channel security display material.

\section{Introduction}

In recent years, stimuli-responsive gels, ${ }^{1-8}$ as a type of smart supramolecular materials, have become one of the most significant realms due to their wide application prospects in chemosensors, ${ }^{9-12}$ biomaterials, ${ }^{13-16}$ displays, ${ }^{17}$ physical materials, ${ }^{18-22}$ chemical engineering ${ }^{23-26}$ and other relevant areas. ${ }^{27-32}$ Taking advantage of the dynamic and reversible nature of noncovalent interactions, such as strong van der Waal's forces, hydrogen bonds and $\pi-\pi$ stacking, ${ }^{33}$ the stimuli-responsive supramolecular gels can sense, process and actuate a response to an external change without assistance. ${ }^{34-36}$ Moreover, metal ionscoordinated supramolecular gels ${ }^{37}$ have become a focus due to their tunable coordination binding strength and fascinating redox, optical, electronic, as well as magnetic properties of the metal ions. ${ }^{38,39}$ These excellent properties would bring benefit to the applications of smart materials.

${ }^{a}$ Key Laboratory of Eco-Environment-Related Polymer Materials, Ministry of Education of China, Key Laboratory of Polymer Materials of Gansu Province, College of Chemistry and Chemical Engineering, Northwest Normal University, Lanzhou, Gansu, 730070, P. R. China.E-mail: linqi2004@126.com; weitaibao@126.com

${ }^{b}$ College of Chemical Engineering, Northwest University for Nationalities, Lanzhou, 730000, P. R. China. E-mail: liujuan656@126.com

$\dagger$ Electronic supplementary information (ESI) available. See DOI: 10.1039/c7ra06238a
However, although a significant amount of effort has been devoted to the development of metal ions coordinated supramolecular gels, ${ }^{\mathbf{4 0}}$ it is still a big challenge to design and synthesize supramolecular gels that can optically sense a given chemical stimulus with a specific selectivity. In view of this, as a part of our research interest in supramolecular chemistry, ${ }^{\mathbf{4 1 - 4 5}}$ we attempted to control the stimuli-response properties of supramolecular gels through the competitive coordination between supramolecular gelators, metal ions and guest compounds.

Herein, we designed and synthesized a gelator $\mathbf{G 1}$ based on multi-assembly driving forces, ${ }^{\mathbf{4 6}-49}$ fluorescent signal groups ${ }^{50}$ and coordination binding sites. ${ }^{51,52}$ The gelator G1 could form a stable supramolecular organogel in various solvents at very low critical gelation concentrations (CGCs). After the addition of $\mathrm{Pb}^{2+}$ to the $\mathbf{G 1}$ ethanol organogel (OG), OG could form a stable $\mathrm{Pb}^{2+}$-coordinated supramolecular metallogel PbG accompanied by the pale blue aggregationinduced fluorescence emission (AIE). ${ }^{53-56}$ The AIE of PbG could be reversibly controlled by iodide anions with a specific selectivity in gel-gel states. PbG could act as not only a convenient reversible $\mathrm{I}^{-}$detection test kit, but also an erasable dual-channel security display material. It is worth mentioning that the security display materials have become of increasing importance..$^{5,58}$ 


\section{Experimental}

As show in Scheme 1, the compound 3,4,5-tris(hexadecyloxy) benzohydrazide was synthesized according to the literaturereported methods. ${ }^{59}$ G1 was synthesized as follow: $p$-nitrobenzaldehyde (1 $\mathrm{mmol}), \quad 3,4,5$-tris(hexadecyloxy)benzohydrazide $(1 \mathrm{mmol})$ and acetic acid $(0.1 \mathrm{~mL}$, as a catalyst) were added to ethanol $(20 \mathrm{~mL})$. Then, the reaction mixture was stirred under refluxed conditions for 24 hours. After the solvent was removed, the precipitated G1 was yielded and recrystallized with $\mathrm{CHCl}_{3}-\mathrm{EtOH}$ to get the solid G1. Yield: $60 \%$, m.p.: $106-110{ }^{\circ} \mathrm{C},{ }^{1} \mathrm{H}$ NMR (400 MHz, $\mathrm{CDCl}_{3}$, Fig. S1†) $\delta 9.30$ (s, $-\mathrm{NH}, 1 \mathrm{H}), 8.26$ (d, J=8.7 Hz, -ArH, $-\mathrm{CH}, 3 \mathrm{H}), 7.90$ (s, -ArH, 2H), 7.07 (s, ArH, 2H), 4.01 (d, $\left.J=3.8 \mathrm{~Hz},-\mathrm{CH}_{2}, 6 \mathrm{H}\right), 1.95-1.71(\mathrm{~m}$, $\left.-\mathrm{CH}_{2}, 6 \mathrm{H}\right), 1.36\left(\mathrm{~m},-\mathrm{CH}_{2}, 78 \mathrm{H}\right), 0.88\left(\mathrm{t}, J=6.5 \mathrm{~Hz},-\mathrm{CH}_{3}, 9 \mathrm{H}\right)$. ${ }^{13} \mathrm{C}$ NMR (150 MHz, $\mathrm{CDCl}_{3}$, Fig. S2 $\dagger$ ) $\delta$ 152.76, 123.99, 107.96, $77.19,76.98,76.77,73.59,73.46,69.44,69.16,60.93,31.91$, $30.30,29.70,29.64,29.62,29.55,29.40,29.38,29.35,29.30$, 26.06, 22.67, 14.38, 14.08; IR (KBr, $\left.\mathrm{cm}^{-1}\right)$ v: $3455(-\mathrm{NH}), 1715$ $(\mathrm{C}=\mathrm{O}), 1650(\mathrm{CH}=\mathrm{N})$. Anal. calcd. for $\mathrm{C}_{62} \mathrm{H}_{107} \mathrm{~N}_{3} \mathrm{O}_{6}: \mathrm{C} 75.03, \mathrm{H}$ 10.40, N 3.98; found: $\mathrm{C} 75.12, \mathrm{H} 10.56, \mathrm{~N} 3.85$. MS: ESI $[\mathrm{M}+\mathrm{H}]^{+}$ $\mathrm{m} / z$ (Fig. S3†) found: 990.8284 , calcd: 990.8233.

\section{Results and discussion}

First, we carefully investigated the gelation properties of G1. As shown in Table $\mathrm{S} 1, \dagger$ the gelator G1 could form a stable supramolecular organogel in various solvents at very low critical gelation concentrations. Among these solvents, the gelator G1 showed the lowest CGC $\left(0.40 \%\right.$, wt $\left./ \mathrm{v} \%, 10 \mathrm{mg} \mathrm{mL} \mathrm{m}^{-1}=1 \%\right)$ and the highest gel-sol transition temperature $\left(78^{\circ} \mathrm{C}\right)$ in ethanol. The G1-based supramolecular organogel OG in ethanol is more stable than the gel in other solutions. Therefore, we investigated the influence of metal ions on the $\mathbf{G 1}$ organogel in ethanol.

Interestingly, after the addition of $\mathrm{Pb}^{2+}$ to the $\mathbf{G 1}$ ethanol organogel (OG), OG could form a stable $\mathrm{Pb}^{2+}$-coordinated supramolecular metallogel PbG. As shown in Fig. 1, PbG has no fluorescence emission in hot ethanol solution $\left(T>T_{\text {gel }}\right)$. However, when the temperature of this hot ethanol solution dropped below the $T_{\text {gel }}$ of PbG, the emission intensity at $340 \mathrm{~nm}$ showed an evident increase and reached a steady state, which indicated that the fluorescence emission of metallogel PbG was aggregation-induced emission (AIE).

The anion response capability of the supramolecular metallogel PbG was primarily investigated by adding various anions in water solutions $\left(\mathrm{AcO}^{-}, \mathrm{HSO}_{4}{ }^{-}, \mathrm{H}_{2} \mathrm{PO}_{4}{ }^{-}, \mathrm{F}^{-}, \mathrm{Cl}^{-}, \mathrm{Br}^{-}, \mathrm{I}^{-}, \mathrm{N}_{3}{ }^{-}\right.$,

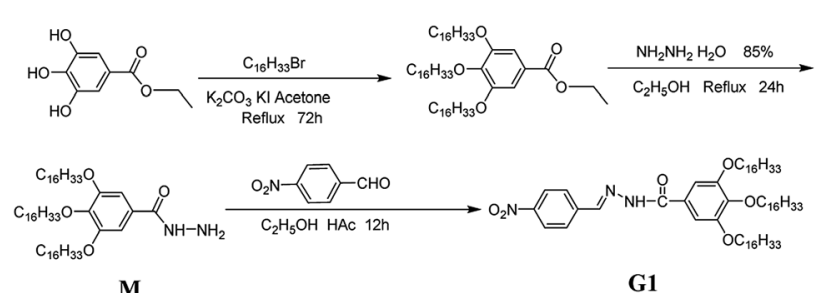

Scheme 1 The synthetic route of organogelator G1.

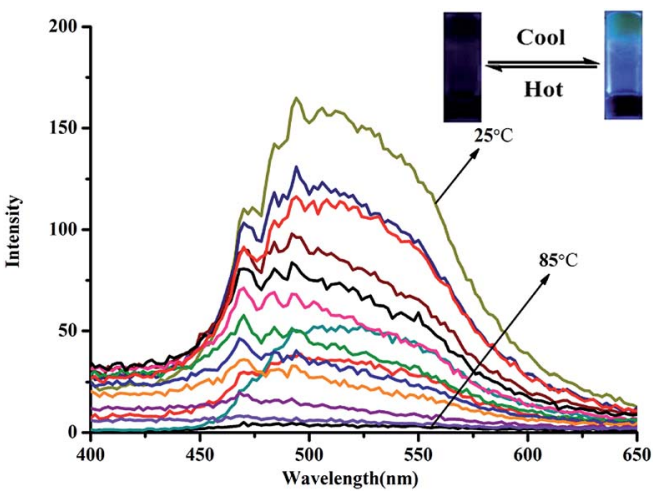

Fig. 1 Temperature dependent fluorescent spectra of the PbG $(1 \%$, in ethanol, $\left.\mathrm{G} 1-\mathrm{Pb}^{2+}=1: 1\right)$ during gelation process $\left(\lambda_{\mathrm{ex}}=340 \mathrm{~nm}\right)$. The temperature was decreased from $85^{\circ} \mathrm{C}$ to $25^{\circ} \mathrm{C}$ and a fluorescence spectrum was recorded every $5^{\circ} \mathrm{C}$.

$\mathrm{SCN}^{-}, \mathrm{ClO}_{4}{ }^{-}, \mathrm{CN}^{-}, \mathrm{CO}_{3}{ }^{2-}, \mathrm{S}^{2-}$ and $\mathrm{SO}_{4}{ }^{2-}, 1 \mathrm{~mol} \mathrm{~L}^{-1}$ ) to PbG. As shown in Fig. 2, when adding water solutions of various anions to the small amount of metallogel PbG on a spot plate, only $\mathrm{I}^{-}$ could quench the fluorescence of PbG, while other anions could not. These results indicated that PbG could selectively sense $\mathrm{I}^{-}$, which was attributed to $\mathrm{I}^{-}$competitively binding with $\mathrm{Pb}^{2+}$.

Moreover, the $\mathrm{I}^{-}$response properties of PbG were investigated by fluorescence titrations. As shown in Fig. 3, with the addition of $\mathrm{I}^{-}$into $\mathbf{P b G}$, the spectra showed evident red shifts, which was attributed to the coordination of $\mathrm{I}^{-}$with $\mathrm{Pb}^{2+}$. In PbG, $\mathrm{Pb}^{2+}$ coordinated with the gelator through the acylhydrazone moiety. When $\mathrm{I}^{-}$was added into $\mathbf{P b G}, \mathrm{Pb}^{2+}$ coordinated with $\mathrm{I}^{-}$and the acylhydrazone moiety was released, which induced the fluorescence spectra of the gel to undergo the red shifts. In addition, the emission intensity at $474 \mathrm{~nm}$ decreased with increasing the concentration of $\mathrm{I}^{-}$. The detection limit of the fluorescence spectra changes, which was calculated on the basis of $3 \delta / S,{ }^{60}$ was $2.037 \times 10^{-6} \mathrm{M}$ (Fig. $\mathrm{S} 4 \dagger$ ) for $\mathrm{I}^{-}$anion.

Interestingly, after the addition of $\mathrm{Pb}^{2+}$ into the $\mathrm{I}^{-}$containing PbG, the fluorescence of PbG recovered, which was attributed to the $\mathrm{Pb}^{2+}$ coordination with $\mathbf{G 1}$ again. These properties

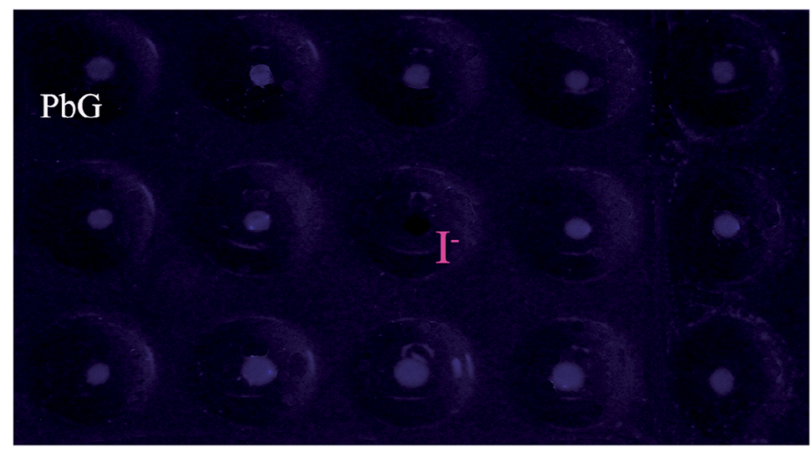

Fig. 2 Photograph of $\mathrm{PbG}\left(1 \%\right.$, in ethanol, $\left.\mathrm{G} 1-\mathrm{Pb}^{2+}=1: 1\right)$ selectively detects $\mathrm{I}^{-}$in the presence of various anions (5 equiv.), from left to right and top to bottom are free $\mathrm{PbG}, \mathrm{PbG}+\mathrm{AcO}^{-}, \mathrm{HSO}_{4}{ }^{-}, \mathrm{H}_{2} \mathrm{PO}_{4}^{-}, \mathrm{F}^{-}, \mathrm{Cl}^{-}$, $\mathrm{Br}^{-}, \mathrm{I}^{-}, \mathrm{N}_{3}^{-}, \mathrm{SCN}^{-}, \mathrm{ClO}_{4}^{-}, \mathrm{CN}^{-}, \mathrm{CO}_{3}{ }^{2-}, \mathrm{S}^{2-}$ and $\mathrm{SO}_{4}{ }^{2-}$, respectively, on a spot plate under UV at $365 \mathrm{~nm}$. 


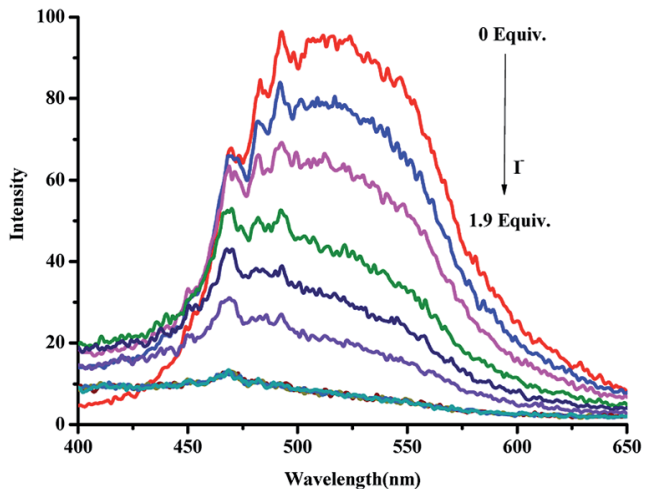

Fig. 3 Fluorescence spectra of $\mathrm{PbG}\left(1 \%\right.$, in ethanol, $\left.\mathrm{G} 1-\mathrm{Pb}^{2+}=1: 1\right)$ with increasing concentration of $\mathrm{I}^{-}$(using $1 \mathrm{~mol} \mathrm{~L}^{-1}$ TBA in water solution as the $\mathrm{I}^{-}$sources), $\lambda_{\mathrm{ex}}=340 \mathrm{~nm}$.

make PbG act as an $\mathrm{I}^{-}$and $\mathrm{Pb}^{2+}$ controlled "on-off-on" fluorescent switch. By alternate addition of $\mathrm{I}^{-}$and $\mathrm{Pb}^{2+}$, the switching could be performed reversibly at least for three cycles with a small fluorescent efficiency loss (Fig. 4).

In order to facilitate the use of the metallogel PbG, the $\mathrm{I}^{-}$ detection film based on PbG was prepared by pouring the heated ethanol solution of PbG onto a clean glass surface and then drying in air. The PbG film was white under natural light and showed a blue fluorescence emission under UV at $365 \mathrm{~nm}$. When a writing brush dipped in $\mathrm{I}^{-}$water solution was used to write on the film, the film did not show any color changes. However, under UV at $365 \mathrm{~nm}$, a clear dark writing image appeared (Fig. 5). This dark writing image could be erased by brushing $\mathrm{Pb}^{2+}$ on the film. More interestingly, when the PbG film containing the invisible $\mathrm{I}^{-}$writing was exposed to iodine vapor, a clear brown writing appeared on the film. However, when the film was put under the room atmosphere for one minute, the brown writing disappeared gradually. Therefore, the PbG film could act as not only a convenient reversible $\mathrm{I}^{-}$ detection test kit, but also an erasable dual-channel security display material.

In order to investigate the self-assembly and stimuliresponse mechanism of $\mathbf{P b G}$, a series of experiments was

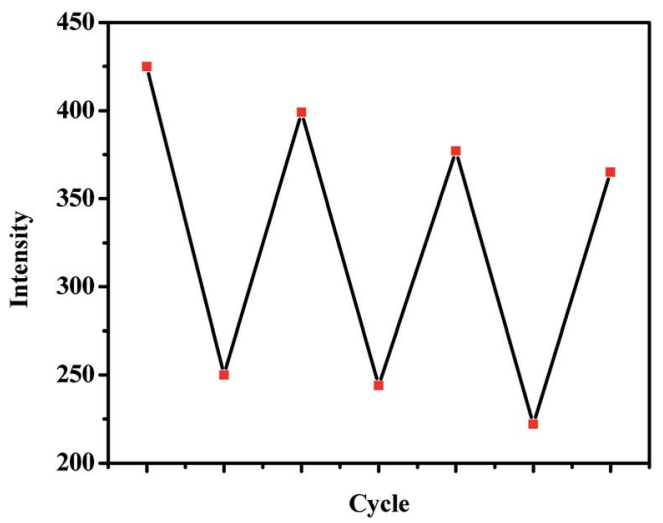

Fig. 4 Fluorescent "on-off-on" cycles of PbG, controlled by the alternative addition of $\mathrm{I}^{-}$and $\mathrm{Pb}^{2+}, \lambda_{\text {ex }}=340 \mathrm{~nm}$.

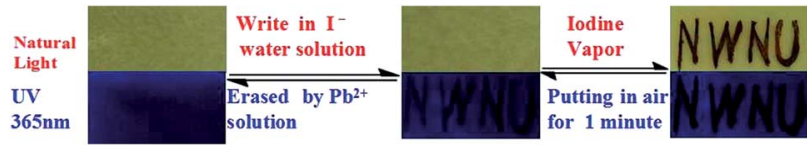

Fig. 5 Writing, erasing and coloration of a natural light invisible image on a PbG supramolecular gel film (obtained from $1 \%$ ethanol metallogel, $\mathrm{PbG}, \mathrm{G} 1-\mathrm{Pb}^{2+}=1: 1$. Writing: write in $\mathrm{I}^{-}$water solution; erasing: brush $\mathrm{Pb}^{2+}$ water solution; coloration: expose the $\mathrm{PbG}$ film into the iodine vapor ca. $5 \mathrm{~s}$ ). The photographs were taken at room temperature under room light and exposed to a $365 \mathrm{~nm}$ UV light.

carried out. First, in the concentration dependent ${ }^{1} \mathrm{H}$ NMR of G1 (Fig. 6), the $-\mathrm{NH}-\left(H_{\mathrm{b}}\right)$ and $-\mathrm{N}=\mathrm{CH}-\left(H_{\mathrm{a}}\right)$ resonance signals showed significant downfield shifts as the concentration of G1 rose. These results revealed that in the gelation process, the $-\mathrm{NH}-\left(H_{\mathrm{b}}\right)$ and $-\mathrm{N}=\mathrm{CH}-\left(H_{\mathrm{a}}\right)$ groups formed hydrogen bonds with the $-\mathrm{C}=\mathrm{O}$ groups on the adjacent gelators. On the other hand, with a gradual increase in concentration, the ${ }^{1} \mathrm{H}$ NMR signal of phenyl protons $\left(H_{\mathrm{c}}, H_{\mathrm{d}}, H_{\mathrm{e}}\right.$, and $H_{\mathrm{f}}$ ) showed an evident upfield shift, indicating that the $\pi-\pi$ stacking interactions between the phenyl groups involved in the gelation process. ${ }^{61}$ Therefore, the gelator G1 self-assembled to supramolecular organogel $\mathbf{O G}$ by the hydrogen bonds, $\pi-\pi$ stacking as well as the vdW existing in the long alkyl chains.

The formation mechanism of supramolecular metallogel was also investigated by ${ }^{1} \mathrm{H}$ NMR titrations, as shown in Fig. 7 . With the addition of $\mathrm{Pb}^{2+}$, the $-\mathrm{NH}-\left(H_{\mathrm{b}}\right)$ group on the gelator showed significant downfield shifts, which indicated that the gelator coordinated with $\mathrm{Pb}^{2+}$ via the acylhydrazone moiety. In addition, in the IR spectra (Fig. S5†) the stretching vibrations of $-\mathrm{C}=\mathrm{O}$ and $-\mathrm{C}=\mathrm{N}-$ of $\mathbf{G 1}$ showed obviously shifts from 3455 and $1650 \mathrm{~cm}^{-1}$ to 3583 and $1588 \mathrm{~cm}^{-1}$, respectively. These phenomena indicated that in PbG, $\mathrm{Pb}^{2+}$ coordinated with the nitrogen and oxygen atoms on the acylhydrazone group.

This presumed self-assembly and coordination mechanism was also supported by the $T_{\text {gel }}$ of $\mathbf{O G}$ and PbG. For instance, as shown in Fig. 8, under the same condition, the $T_{\text {gel }}$ of OG was significantly higher than that of PbG. The large differences of

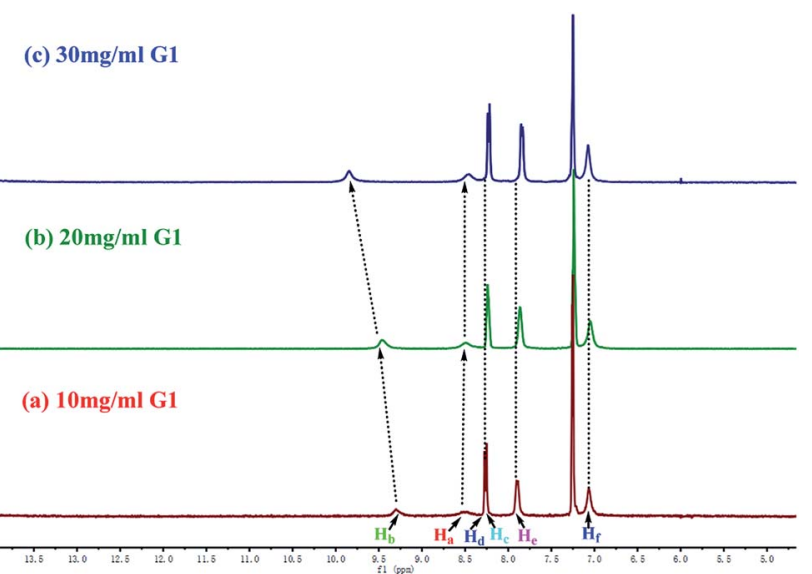

Fig. 6 Partial ${ }^{1} \mathrm{H}$ NMR spectra of $\mathrm{G} 1$ in $\mathrm{CDCl}_{3}$ with different concentrations. 


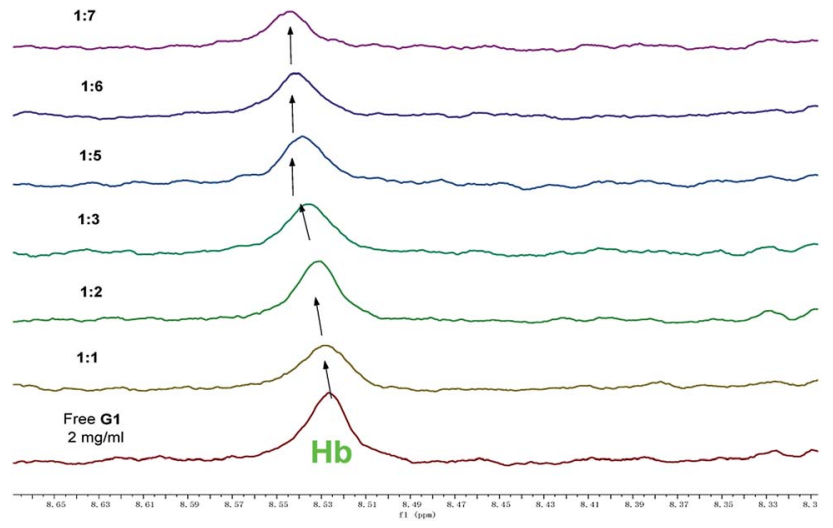

Fig. 7 Partial ${ }^{1} \mathrm{H}$ NMR spectra of G1 (2 $\left.\mathrm{mg} \mathrm{mL}^{-1}\right)$ and G1 mixed with $1-$ 7 equiv. of $\mathrm{Pb}^{2+}$ in ethanol- $d_{6}$.

$T_{\text {gel }}$ between OG and PbG were ascribed to the breakage of intermolecular hydrogen bonds between $-\mathrm{N}=\mathrm{C}-\mathrm{H}$ on one gelator and $-\mathrm{C}=\mathrm{O}$ on the other one in $\mathbf{O G}$, which was caused by the coordination of $\mathrm{Pb}^{2+}$ with the gelator G1. Moreover, the $\mathrm{Pb}^{2+}$ coordination process reduced the distance of $\pi-\pi$ stacking between the phenyls, which enhanced the aggregation induced emission of PbG.

This proposed mechanism was also supported by the XRD patterns (Fig. S6 $\dagger$ ). The XRD patterns of OG, PbG and the PbG treated with $\mathrm{I}^{-}$showed the peaks at $2 \theta=18.62-27.70^{\circ}$, corresponding to the $d$ spacing $3.5 \AA$, $3.45 \AA$, and $3.8 \AA$, respectively. As shown in Scheme 2 and Fig. S6, $\dagger$ in OG, the peaks at $21.28^{\circ}$ and the $d$ spacing $3.5 \AA$ were attributed to the $\pi-\pi$ stacking, which existed in the phenyl groups of OG. While, in PbG, the $d$ spacing changed to $3.45 \AA$, which was attributed to the $\mathrm{Pb}^{2+}$ coordination process reducing the distance of $\pi-\pi$ stacking between the phenyls. Meanwhile, the $d$ spacing $3.8 \AA$ was attributed to the interlamellar spacing between the supramolecular chains. In addition, after the formation of PbG, the peaks of OG (at $2 \theta=21.28,23.22,23.90,25.30^{\circ}$ ) disappeared and these peaks reappeared after PbG was treated with $\mathrm{I}^{-}$. These phenomena confirmed that $\mathrm{Pb}^{2+}$ coordinated with $\mathbf{O G}$ and induced a change in the XRD pattern of OG, while the addition of $\mathrm{I}^{-}$into $\mathbf{P b G}$ induced the competitive coordination of $\mathrm{I}^{-}$with

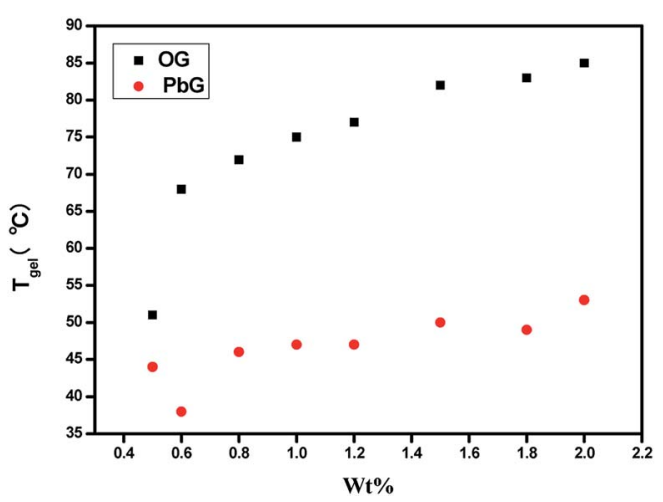

Fig. 8 Plots of $T_{\text {gel }}$ against the concentrations of organogel $O G$ and metallogels $\mathrm{PbG}\left(\mathrm{G} 1-\mathrm{Pb}^{2+}=1: 1\right)$ in ethanol.

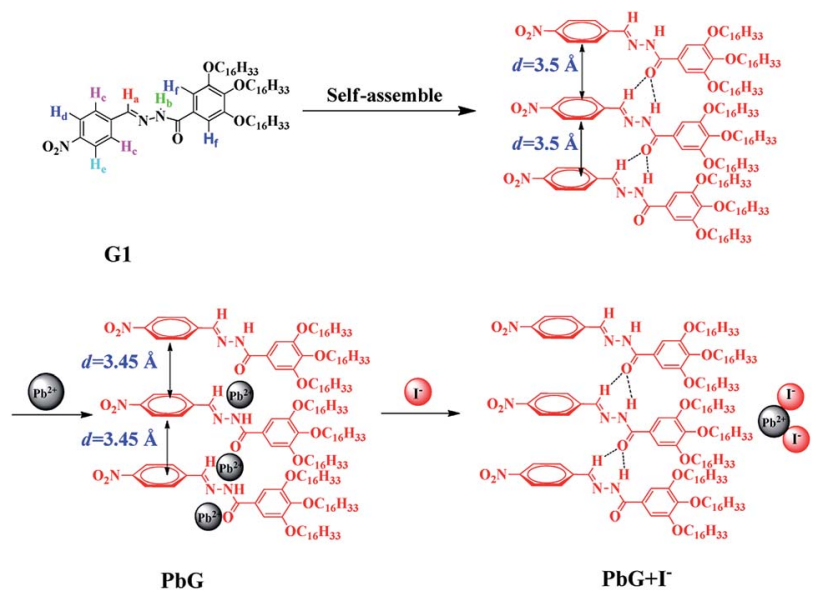

Scheme 2 Chemical structure of the G1 and the presumed self assembly and reversible stimuli-response mechanism.

$\mathrm{Pb}^{2+}$ and led to the recovery of XRD peaks. According to ${ }^{1} \mathrm{H}$ NMR, IR and XRD, the ion response mechanism of OG and PbG could be presumed as in Scheme 2 .

To get further insight into the morphological features of the supramolecular organogel OG, metallogel PbG and PbG treated with $\mathrm{I}^{-}$, SEM studies were carried out with their xerogels, respectively. As shown in Fig. S7, $\uparrow$ the SEM images of OG showed an overlapped rugate layer structure. The metallogel PbG also showed overlapped rugate layer structures and the aggregation structure of layer was compacted. However, after $\mathrm{I}^{-}$ was added into the PbG xerogel, the micro states experienced obvious changes. There were a large number of micro cavities formed in the xerogel of PbG. These micro cavities provided the PbG xerogel with the properties for the adsorption of iodine vapor. Therefore, the mechanism of iodine vapor-caused color change could be attributed to the iodine vapor adsorption into these micro cavities.

\section{Conclusions}

In summary, a novel supramolecular gelator G1 has been designed and synthesized. The gelator $\mathbf{G 1}$ could form a stable supramolecular metallogel PbG. Through the competitive coordination of $\mathrm{Pb}^{2+}$ and $\mathrm{I}^{-}$with the gelator $\mathbf{G 1}$, the aggregation-induced emission of the supramolecular metallogel PbG was controlled as "on-off-on”. More interestingly, after $\mathrm{Pb}^{2+}$ competitive coordinated with $\mathrm{I}^{-}$, there were a large number of micro cavities formed in the PbG xerogel, which enabled the PbG xerogel to absorb the iodine vapor and show a brown color. PbG could act as not only a convenient high selective and sensitive $\mathrm{I}^{-}$detection test kit, but also an erasable dual-channel secret documentation medium.

\section{Acknowledgements}

This study was supported by the National Natural Science Foundation of China (NSFC) (No. 21662031; 21661028; $21574104 ; 21262032)$ and the Program for Changjiang Scholars 
and Innovative Research Team in University of Ministry of Education of China (IRT 15R56).

\section{Notes and references}

1 M. D. Segarra-Maset, V. J. Nebot, J. F. Miravet and B. Escuder, Chem. Soc. Rev., 2013, 42, 7086.

2 H. Tan, X. Ma and M. Fu, Bull. Mater. Sci., 2013, 36, 153.

3 L. Predoana, I. Stanciu, M. Anastasescu, J. M. CalderonMoreno, M. Stoica, S. Preda, M. Gartner and M. Zaharescu, J. Sol-Gel Sci. Technol., 2016, 78, 589.

4 Z. X. Liu, Y. Feng, Z. C. Yan, Y. M. He, C. Y. Liu and Q. H. Fan, Chem. Mater., 2012, 24, 3751.

5 Q. Xia, Y. Mao, J. Wu, T. Shu and T. Yi, J. Mater. Chem. C, 2014, 2, 1854.

6 S. Basak, J. Nanda and A. Banerjee, Chem. Commun., 2014, 50, 2356.

7 A. S. Lee, S. S. Choi, K. Y. Baek and S. S. Hwang, Inorg. Chem. Commun., 2016, 73, 7.

8 S. S. Babu, V. K. Praveen and A. Ajayaghosh, Chem. Rev., 2014, 114, 1973.

9 V. Lozano, R. Hernández, A. Ardá, J. Jiménez-Barbero, C. Mijangos and M. J. Pérez-Pérez, J. Mater. Chem., 2011, 21, 8862.

10 Y. He, Z. Guo, P. Jin, C. Jiao, H. Tian and W. Zhu, Ind. Eng. Chem. Res., 2015, 54, 2886.

11 C. D. Jones and J. W. Steed, Chem. Soc. Rev., 2016, 45, 6546.

12 P. Xue, J. Ding, M. Jin and R. Lu, J. Mater. Chem. C, 2017, 5, 5299.

13 Q. Duan, Y. Cao, Y. Li, X. Hu, T. Xiao, C. Lin, Y. Pan and L. Wang, J. Am. Chem. Soc., 2013, 135, 10542.

14 G. Visioli, A. Comastri, D. Imperiale, G. Paredi, A. Faccini and N. Marmiroli, Food Anal. Methods, 2016, 9, 469.

15 J. Jielile, A. Jialili, G. Sabirhazi, N. Shawutali, D. Redati, J. Chen, J. Bai and K. Aldyarhan, Appl. Biochem. Biotechnol., 2012, 166, 521.

16 Y. Cao, Y. Li, X. Y. Hu, X. Zou, S. Xiong, C. Lin and L. Wang, Chem. Mater., 2015, 27, 1110.

17 J. Zhou, X. Du, Y. Gao, J. Shi and B. Xu, J. Am. Chem. Soc., 2014, 136, 2970.

18 G. Sun, J. Xiao, M. Lu, H. Wang, X. Chen, Y. Yu, Y. Pan and Y. Wang, Appl. Biochem. Biotechnol., 2015, 175, 400.

19 T. Kitahara, M. Shirakawa, S. Kawano, U. Beginn, N. Fujita and S. Shinkai, J. Am. Chem. Soc., 2005, 127, 14980.

20 X. Y. Hu, T. Xiao, C. Lin, F. Huang and L. Wang, Acc. Chem. Res., 2014, 47, 2041.

21 G. Mun, H. Choi, N. Im, J. Ahn, J. Park, H. Seo, Y. Choi, J. H. Lee and J. H. Jung, RSC Adv., 2017, 7, 26827.

22 C. Kim, K. Y. Kim, J. H. Lee, J. Ahn, K. Sakurai, S. S. Lee and J. H. Jung, ACS Appl. Mater. Interfaces, 2017, 9, 3799.

23 E. P. Simonenko, A. V. Derbenev, N. P. Simonenko, V. G. Sevastyanov and N. T. Kuznetsov, Russ. J. Inorg. Chem., 2015, 60, 1444.

24 Z. Cheng, J. Liao, B. He, F. Zhang, F. Zhang, X. Huang and L. Zhou, ACS Sustainable Chem. Eng., 2015, 3, 1677.

25 M. Jiang, J. Zhu, C. Chen, Y. Lu, Y. Ge and X. Zhang, ACS Appl. Mater. Interfaces, 2016, 8, 3473.
26 Y. Cao, X. Y. Hu, Y. Li, X. Zou, S. Xiong, C. Lin, Y. Z. Shen and L. Wang, J. Am. Chem. Soc., 2014, 136, 10762.

27 N. V. V. Satya Bhushan and R. N. Nayak, J. Oral Maxillofac. Surg., 2010, 9, 119.

28 J. A. Foster, K. K. Damodaran, A. Maurin, G. M. Day, H. P. G. Thompson, G. J. Cameron, J. C. Bernal and J. W. Steed, Chem. Sci., 2017, 8, 78.

29 H. Wang, X. Ji, Z. Li, C. N. Zhu, X. Yang, T. Li, Z. L. Wu and F. Huang, Materials Chemistry Frontiers, 2017, 1, 167.

30 P. Hallegot, G. Hussler, V. Jeanne-Rose, F. Leroy, F. Pineau and H. Samain, J. Sol-Gel Sci. Technol., 2016, 79, 365.

31 S. Lee and S. T. Nguyen, Macromolecules, 2013, 46, 9169.

32 P. Xue, Q. Xu, P. Gong, C. Qian, A. Ren, Y. Zhang and R. Lu, Chem. Commun., 2013, 49, 5838.

33 T. Ghane, D. Nozaki, A. Dianat, A. Vladyka, R. Gutierrez, J. P. Chinta, S. Yitzchaik, M. Calame and G. Cuniberti, J. Phys. Chem. C, 2015, 119, 6344.

34 N. Song, D. X. Chen, Y. C. Qiu, X. Y. Yang, B. Xu, W. Tian and Y. W. Yang, Chem. Commun., 2014, 50, 8231.

35 X. Yan, D. Xu, X. Chi, J. Chen, S. Dong, X. Ding, Y. Yu and F. Huang, Adv. Mater., 2012, 24, 362.

36 Y. M. Zhang, B. B. Shi, H. Li, W. J. Qu, G. Y. Gao, Q. Lin, H. Yao and T. B. Wei, Polym. Chem., 2014, 5, 4722.

37 Q. Lin, B. Sun, Q. P. Yang, Y. P. Fu, X. Zhu, T. B. Wei and Y. M. Zhang, Chem.-Eur. J., 2014, 20, 11457.

38 K. Lalitha, V. Sridharan, C. U. Maheswari, P. K. Vemula and S. Nagarajan, Chem. Commun., 2017, 53, 1538.

39 Y. Zhang, B. Zhang, Y. Kuang, Y. Gao, J. Shi, X. X. Zhang and B. Xu, J. Am. Chem. Soc., 2013, 135, 5008.

40 S. S. Abolmaali, A. Tamaddon, H. Najafi and R. Dinarvand, J. Inorg. Organomet. Polym., 2014, 4, 977.

41 Q. Lin, T. T. Lu, X. Zhu, B. Sun, Q. P. Yang, T. B. Wei and Y. M. Zhang, Chem. Commun., 2015, 51, 1635.

42 Q. Lin, T. T. Lu, J. C. Lou, G. Y. Wu, T. B. Wei and Y. M. Zhang, Chem. Commun., 2015, 51, 12224.

43 Q. Lin, Q. P. Yang, B. Sun, J. C. Lou, T. B. Wei and Y. M. Zhang, RSC Adv., 2015, 5, 11786.

44 Q. Lin, F. Zheng, L. Liu, P. P. Mao, Y. M. Zhang, H. Yao and T. B. Wei, RSC Adv., 2016, 6, 11928.

45 Q. Lin, P. P. Mao, L. Liu, J. Liu, Y. M. Zhang, H. Yao and T. B. Wei, RSC Adv., 2017, 7, 11206.

46 M. H. Liu and Y. Fang, Chin. Sci. Bull., 2012, 57, 4245.

47 C. Zhao, X. Zhang, K. Li, S. Zhu, Z. Guo, L. Zhang, F. Wang, Q. Fei, S. Luo, P. Shi, H. Tian and W. H. Zhu, J. Am. Chem. Soc., 2015, 137, 8490.

48 Q. Lin, Q. P. Yang, B. Sun, Y. P. Fu, X. Zhu, T. B. Wei and Y. M. Zhang, Soft Matter, 2014, 10, 8427.

49 Y. Gong, T. Jiao, Q. Hu, N. Cheng, W. Xu, Y. Bi and L. Yu, J. Phys. Chem. C, 2015, 119, 16349.

50 X. Ji, Y. Yao, J. Li, X. Yan and F. Huang, J. Am. Chem. Soc., 2013, 135, 74.

51 Q. Lin, B. Sun, Q. P. Yang, Y. P. Fu, X. Zhu, Y. M. Zhang and T. B. Wei, Chem. Commun., 2014, 50, 10669.

52 D. H. Qu, Q. C. Wang, Q. W. Zhang, X. Ma and H. Tian, Chem. Rev., 2015, 115, 7543.

53 Y. Hong, J. W. Y. Lam and B. Z. Tang, Chem. Soc. Rev., 2011, 40, 5361. 
54 W. Lei, Y. Liu, J. Bai, Y. Dai, Y. Kan, T. Chen and B. Yin, Tetrahedron, 2015, 71, 5465.

55 K. Duraimurugan, J. Sivamani, M. Sathiyaraj, V. Thiagarajan and V. Siva, J. Fluoresc., 2016, 26, 1211.

56 X. Wu, H. Li, Y. Kan and B. Yin, Dalton Trans., 2013, 42, 16302.

57 A. Kishimura, T. Yamashita, K. Yamaguchi and T. Aida, Nat. Mater., 2005, 4, 546.
58 N. Tamaoki, A. V. Parfenov, A. Masaki and H. Matsuda, Adv. Mater., 1997, 9, 1102.

59 Y. P. Fu, Q. Lin, T. B. Wei, P. Chen, X. Zhu, X. Liu and Y. M. Zhang, Chem. Reagents, 2013, 35, 367.

60 Analytical Methods Committee, Analyst, 1987, 112, 199.

61 C. Po, Z. Ke, A. Y. Y. Tam, H. F. Chow and V. W. W. Yam, Chem.-Eur. J., 2013, 19, 15735. 